\title{
Enhancing Hepatoprotective Bioactive's from Phyllanthus Amaraus Through Immobilization
}

\author{
J. S. Thakur and M. D. Kharya
}

\begin{abstract}
Phyllanthus amarus plant is used in traditional system of medicine as hepatoprotective drug for which the major lignans phyllanthin and hypophyllanthin are responsible. As so far no significant work has been done on culture aspect of this plant, hence realizing the hepatoprotective potential, the present investigation was undertaken.

A cost effective process was developed for enhancing phyllanthin and hypophyllanthin utilizing immobilization technique. HPTLC was used to compare phyllanthin and hypophyllanthin contents in calcium alginate immobilized cells obtained from fresh grown plants and M. S. medium was supplemented with different precursors and phytohormones, for treatment with kinetin, napthalene acetic acid, chitosan and cinnamic acid solution to make whole process commercially viable. It was revealed that cinnamic acid and chitosan in low concentration enhances phyllanthin and hypophyllanthin yield as compared to control. The study revealed that increase in the content of phyllanthin and hypophyllanthin was precursor concentration dependent and cinnamic acid treatment give maximum yield of hepatoprotective bioactives as compared to other precursor and phytohormones used.
\end{abstract}

Index Terms-Hepatoprotective, HPTLC, Immobilization, Precursor.

\section{INTRODUCTION}

The aim of plant biotechnology research is to optimize the concentrations of precursors, abiotic and biotic elicitors with duration of their contact for maximum response to the production of targeted secondary metabolite is very much desired.

Liver one of the human body organs performs many vital functions including digestion. Another important role is to detoxify harmful and unwanted substances in the body. During this detoxification process, the liver suffers from challenges affecting the hepatic architecture and hepatocytes. In general the liver suffers from hepatotoxicity which damages it. Antihepatotoxic herbs restore the bile flow and reduce total bilirubin, biliverdin, triglycerides, cholesterol and total lipids in liver.[1]

To overcome these complications a large number of herbal drugs are prescribed e.g.

(1) Phyllanthus niruri, (2) Ocimum sanctum, (3) Tephrosia purpurea, (4) Andrographis paniculata, (5) Eclipta alba and (6) Terminalia chebula. They contain polyphenols, tannins, lignans and alkaloids which possess serum bilirubin, reducing the effect on the hepatic tissues

Manuscript received September 9, 2011; revised November 28, 2011.

Authors are with Department of Pharmaceutical Sciences, Dr. Hari Singh Gour Central University, Sagar (M.P.) 470003 India (Tel.: 011-7582 -222554; fax: 011-7582-230063; e-mail: jaiwantthakur@gmail.com). without any adverse effect. These constituents act as excellent hepatoprotectives, in the treatment of jaundice and liver cirrhosis.

Phyllanthus amarus is an important hepatoprotective drug being used since time immemorial. The hepatoprotective activity has been reported from phyllanthin and hypophyllanthin present in P. amarus. Although it is highly valuable as hepatoprotective agent, $P$. amarus suffers from the problem of short supply due to its low herbage, availability in limited duration and stringent requirement of climatic condition. Phyllanthus amarus (Euphorbiaceae) commonly called Bhui amla, though common to central and south India, is indigenous to the rain forests of Amazon and other tropical areas of world. Due to its hepatoprotective property, it is in great demand. However, scanty growth and short life span (July to October) and requirement of damp weather for growth are the factors responsible for the short supply of $P$. amarus. These factors make this plant a suitable candidature for exploitation through biotechnology for production of its hepatoprotective bioactives [2]

To overcome these problems it was thought to use biotechnology for producing the bioactives -phyllanthin and hypophyllanthin using plant tissue culture technology utilizing Phyllanthus amarus.

\section{EXPERIMENTAL}

Fresh leaves of $P$. amarus collected from medicinal plant garden of Department of Pharmaceutical Sciences, Dr. H. S. Gour Central University, Sagar (M.P.) India, were authenticated (Herbarium No.QDS/3/ 99/09) from Central Institute of Medicinal and Aromatic Plants (CIMAP), Lucknow (U.P.) India.

From literature it was revealed that chitosan and cinnamic acid play an important role in enhancing the secondary metabolite production in medicinal plants. It was also observed that kinetin and napthalene acetic acid also exert noticeable role in the enhancement of bioactives by immobilization.

These precursors and phytohormones are therefore selected for studying their role in production of important bioactives from $P$. amarus through immobilized system.

\section{Sterilization OF MATERIAL AND PREPARATION OF ALGINATE BEADS FOR IMMOBILIZATION}

The collected fresh leaves ( $25 \mathrm{gm})$ of $P$. amarus were washed with running tap water, followed by $2 \%$ tween solution, rewashed thoroughly with distilled water, and then sterilized with $70 \%$ ethanol. The leaves were subsequently surface sterilized with $0.1 \%$ mercuric chloride solution and were washed thoroughly with sterilized water in aseptic 
condition. Then the leaves were crushed finely by using sterilized pestle mortar to get cell homogenate of $P$. amarus leaves [3].

Over-night stored sodium alginate solution $20 \mathrm{ml} \mathrm{(5 \% )}$ was mixed thoroughly with cell homogenate for 30 minute to eliminate air bubbles and to enhance viscosity. The beads, from cell homogenate were prepared using $25 \mathrm{ml}$ injection syringe and prepared beads were suspended in $(2 \% \mathrm{w} / \mathrm{v})$ calcium chloride solution. The alginate beads were then washed with $0.9 \%$ sterilized saline solution and transferred into $(100 \mathrm{ml})$ sterilized conical flask containing $50 \mathrm{ml} \mathrm{MS}$ medium. This immobilized cell cultures of $P$. amarus leaves was used in experimentation for obtaining maximum yield of bioactives phyllanthin and hypophyllanthin.

\section{A. Effect of Kinetin Treatment}

6-furfurylaminopurine a precursor of amino acids is cytokinin that promotes cell division. Kinetin is used in plant suspension culture for inducing formation of cells in lower auxin concentration. Stock solution $\left(1: 10^{4}\right)$ of kinetin was made with sterilized distilled water.

The above experimental procedure was followed to prepare alginate beads of $P$. amarus leaves. Four sets of triplicate sterilized conical flasks were taken and labelled as KT (where as to control flask no kinetin solution was added) KT1, KT2 and KT3. In each set of flask containing $50 \mathrm{~mL}$ MS medium 5, 10 and $20 \mathrm{~mL}$ of kinetin solution was added. The flasks were cotton plugged and kept in shaking incubator $\left(25 \pm 2^{\circ} \mathrm{C}\right)$ between $80-100 \mathrm{rpm}$ for 14 days. Immobilized cell culture $(20 \mathrm{~mL})$ from each flask was withdrawn and HPTLC analysis of the samples was done for phyllanthin and hypophyllanthin content.

It was found that as the concentration of kinetin solution increased from 5 to $20 \mathrm{~mL}$, the content of bioactives phyllanthin and hypophyllanthin also enhanced from 0.122 to $0.126 \%$ as compared to control $0.120 \%$. The increase in yield of these bioactives $0.126 \%$ with $20 \mathrm{~mL}$ of kinetic solution was to the tune of $5 \%$ (Table I, Fig. 2).

TABLE I: HPTLC ANALYSIS OF IMMOBILIZED P. AMARUS CELL SYSTEM FOR PHYLLANTHIN AND HYPOPHYLLANTHIN CONTENT WITH KINETIN

\begin{tabular}{|l|l|l|l|}
\hline Flask & $\begin{array}{l}\text { Kinetin } \\
\mathbf{( 1 : 1 0 4 )} \mathbf{~ m L}\end{array}$ & $\begin{array}{l}\text { Phyllanthin and hypophy- } \\
\text { llanthin content }(\mathbf{w} / \mathbf{w})^{*}\end{array}$ & $\begin{array}{l}\text { \% increase } \\
\text { compared to control }\end{array}$ \\
\hline KT & Control & $0.120 \pm 0.001$ & 0 \\
\hline KT1 & 5 & $0.122 \pm 0.001$ & 1.67 \\
\hline KT2 & 10 & $0.124 \pm 0.002$ & 3.33 \\
\hline KT3 & 20 & $0.126 \pm 0.001$ & 5.00 \\
\hline
\end{tabular}

*Readings are average mean of 3 set of flasks

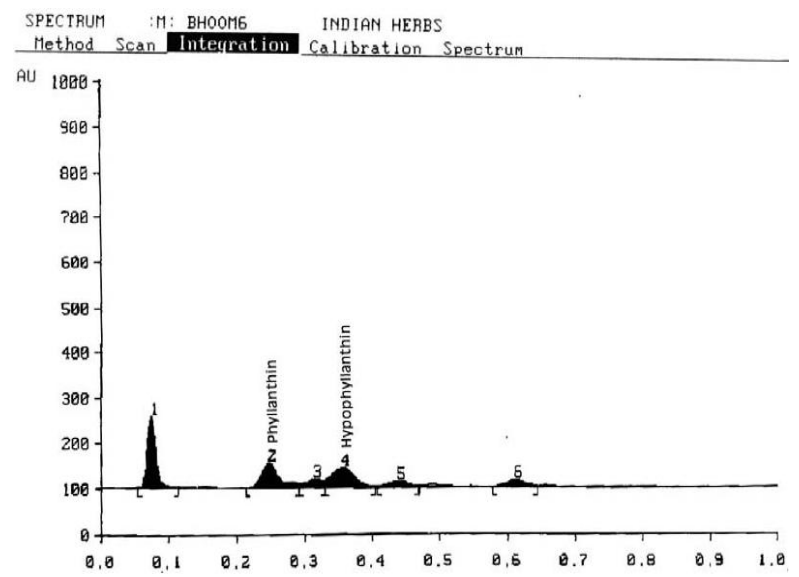

Fig. 1. HPTLC chromatogram showing the metabolite production profile of immobilized P.amarus as control.

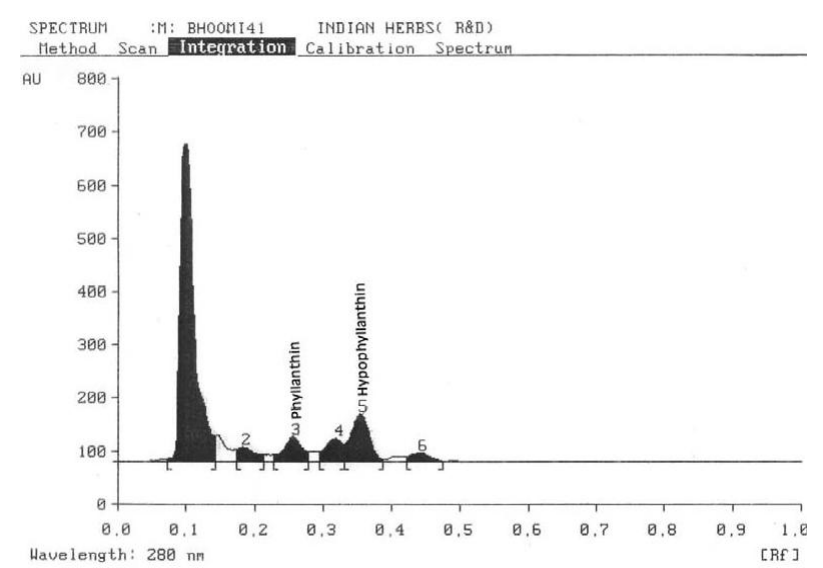

Fig. 2. HPTLC chromatogram showing metabolite production profile of immobilized $P$. amarus cells by medium elicitation with $20 \mathrm{~mL}$ Kinetin.

\section{B. Effect of Napthalene Acetic Acid Treatment}

It is a phytohormone in the auxin family and is used for vegetative propagation of plants from stem and leaf cutting in plant tissue culture, by altering the osmotically active contents of cell vacuole during cell expansion.

$1 \mathrm{gm}$ NAA was weighed dissolved in $10 \mathrm{~mL}$ of $1 \mathrm{~N}$ sodium hydroxide solution and the volume was made upto $100 \mathrm{~mL}$ with double distilled water (1\% stock solution). Previous experimental procedure was followed, three set of sterilized conical flasks (in triplicate) were taken, labeled as N1, N2 and $\mathrm{N} 3$ containing 50mL MS medium into which 5, 10 and $20 \mathrm{~mL}$ of $1 \%$ NAA solution was added than incubated for 14 days and $20 \mathrm{~mL}$ immobilized cell culture from each flask was withdrawn and HPTLC analysis was done for content of phyllanthin and hypophyllanthin.

TABLE II: HPTLC ANALYSIS OF IMMOBILIZED $P$. AMARUS CELl SySTEM FOR PHYLlanthin AND Hypophyllanthin CONTENT TREATED With NAPTHALENE ACETIC ACID

\begin{tabular}{|l|l|c|c|}
\hline Flask & $\begin{array}{l}\text { Napthalene acetic } \\
\text { acid (1\%)mL }\end{array}$ & $\begin{array}{c}\text { Phyllanthin and } \\
\text { hypophyllanthin (w/w)* }\end{array}$ & $\begin{array}{c}\text { \% increase } \\
\text { compared to control }\end{array}$ \\
\hline NC & Control & $0.120 \pm 0.001$ & 0 \\
\hline N1 & 5 & $0.175 \pm 0.002$ & 46 \\
\hline N2 & 10 & $0.210 \pm 0.001$ & 75 \\
\hline N3 & 20 & $0.225 \pm 0.002$ & 88 \\
\hline
\end{tabular}

*Readings are average mean of 3 set of flasks

After HPTLC analysis it was found that treatment with $1 \%$ Napthalene acetic acid solution enhances the content of phyllanthin and hypophyllanthin from control $0.120 \%$ to $0.175 \%, 0.210 \%$ and $0.225 \%$ respectively. The increase in yield of these bioactives $0.225 \%$ with $30 \mathrm{~mL}$ was to the tune of $88 \%$ in immobilized cell cultures (Table II, Fig.3).

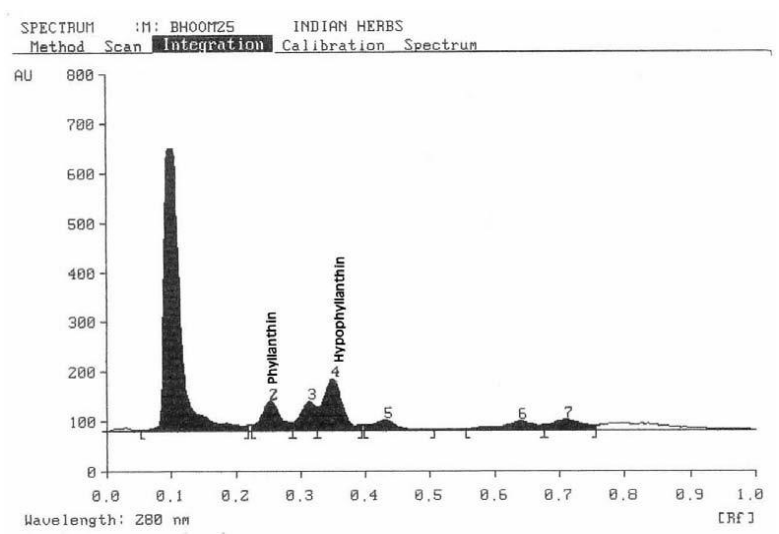

Fig. 3. HPTLC chromatogram showing metabolite production profile of immobilized $P$. amarus cells by medium elicitation with $20 \mathrm{~mL}$ Napthalene acetic acid. 


\section{Effect of Chitosan Treatment}

It is a linear polysaccharide produced commercially by deacetylation of chitin, from exoskeleton of crabs, shrimp etc. and cell wall of fungi.

TABLE III: HPTLC ANALYSIS OF IMMOBILIZED P. AMARUS CELL SYSTEM FOR PHYLLANTHIN AND HYPOPHYLLANTHIN CONTENT WITH CHITOSAN

\begin{tabular}{|l|c|c|c|}
\hline Flask & $\begin{array}{c}\text { Chitosan } \\
(\mathbf{1 \%}) \mathbf{~ m l}\end{array}$ & $\begin{array}{c}\text { Phyllanthin and } \\
\text { hypophyllanthin }(\mathbf{w} / \mathbf{w})\end{array}$ & $\begin{array}{c}\text { \% increase compared } \\
\text { to control }\end{array}$ \\
\hline AC & Control & $0.120 \pm 0.001$ & 0 \\
\hline CT1 & 5 & $0.261 \pm 0.001$ & 117 \\
\hline CT2 & 10 & $0.305 \pm 0.002$ & 154 \\
\hline CT3 & 20 & $0.405 \pm 0.001$ & 238 \\
\hline
\end{tabular}

*Readings are average mean of 3 set of flasks

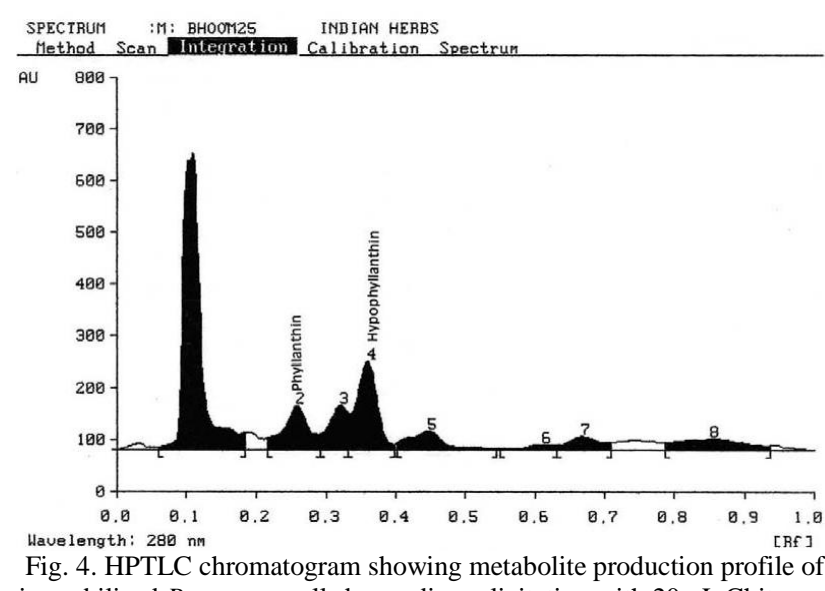

Chitosan A.R (1gm) was dissolved in $100 \mathrm{ml}$ of distilled water by heating at $60^{\circ} \mathrm{C}$ for 15 minutes with $2 \mathrm{ml}$ of glacial acetic acid to make $1 \%(\mathrm{w} / \mathrm{v})$ chitosan solution. The $\mathrm{pH}$ of the solution $(100 \mathrm{ml})$ was adjusted to 5.5 with $1 \mathrm{~N}$ sodium hydroxide solution and autoclaved at $120^{\circ} \mathrm{C}$ (15 lbs/sq.inch) for 20 minutes and was filter sterilized before addition to the immobilized cell culture. Four set (in triplicate) sterilized conical flasks were taken with $50 \mathrm{ml} \mathrm{MS}$ medium and labelled as AC [control] CT1, CT2 and CT3, containing $25 \mathrm{gm}$ alginate beads of P.amarus. Into CT1, CT2 and CT3 flasks 5, 10 and $20 \mathrm{ml}$ of $1 \%$ chitosan solution was added and incubated for 14 days in incubator cum shaker at $25 \pm 2^{\circ} \mathrm{C}$ between 80 to 100 r.p.m. Immobilized cell culture $(20 \mathrm{ml})$ from each flask was withdrawn and HPTLC analysis was done for content of phyllanthin and hypophyllanthin in control and treated flasks.

From the experimental data it was observed that as the concentration of chitosan in immobilized cell culture increased from 5 to $20 \mathrm{~mL}$, the bioactives phyllanthin and hypophyllanthin enhanced from $0.261 \%$ to $0.405 \%$ which was higher than the control $0.120 \%$. The maximum increase in the yield of bioactives $(0.405 \%)$ with $20 \mathrm{~mL}$ of $1 \%$ chitosan solution was to the tune of $238 \%$ (Table III, Fig.4).

\section{Effect of Cinnamic Acid Treatment}

It is a white crystalline acid, slightly soluble in water. Cinnamic acid is a precursor of many alkaloids, aromatic amino acids and indole derivatives.

MS Medium was supplemented with Cinnamic acid by preparing $1 \%$ stock solution $(100 \mathrm{~mL})$ and was sterilized by filtration using $0.2 \mu$ microfilter.

To five sets of sterilized conical flasks containing alginate beads of P.amarus leaves (in triplicate) of $100 \mathrm{~mL}$ capacity containing $50 \mathrm{~mL}$ MS medium, prepared solution of cinnamic acid was added @ 2, 4,6 and 8mL respectively in the flasks, labelled as A1, A2, A3 and A4 whereas to control flask (AC) no cinnamic acid solution was added and hence it was treated as control. After 14 days of incubation $20 \mathrm{~mL}$ sample was withdrawn from each flask and collected samples were analysed, for their phyllanthin and hypophyllanthin content in immobilized cells by HPTLC.

Control sample after quantification showed $0.120 \%$ of phyllanthin and hypophyllanthin by HPTLC analysis. After adding 2 and $4 \mathrm{~mL}$ cinnamic acid in MS medium, the yield of $0.250 \%$ and $0.261 \%$ phyllanthin and hypophyllanthin from immobilized cell system was found to be $0.365 \%$ and $0.422 \%$ by adding 6 and $8 \mathrm{~mL}$ of $1 \%$ cinnamic acid solution. The highest increase in bioactives was $0.422 \%$ with the addition of $8 \mathrm{~mL}$ cinnamic acid. It shows that the highest concentration of phyllanthin and hypophyllanthin increased by $252 \%$ as compared to control $0.120 \%$ by the incorporation of cinnamic acid in the medium (Table IV, Fig. 5).

TABLE IV: HPTLC ANALYSIS OF IMMOBILIZED P. AMARUS CELL SYSTEM FOR PHYLLANTHIN AND HYPOPHYLLANTHIN CONTENT WITH CINNAMIC ACID.

\begin{tabular}{|l|l|c|c|}
\hline Flask & $\begin{array}{l}\text { Cinnamic acid } \\
(\mathbf{1 \% )} \mathbf{~ m L}\end{array}$ & $\begin{array}{c}\text { Phyllanthin and } \\
\text { hypophyllanthin }(\mathbf{w} / \mathbf{w}) *\end{array}$ & $\begin{array}{c}\text { \% increase com- } \\
\text { pared to control }\end{array}$ \\
\hline AC & Control & $0.120 \pm 0.001$ & 0 \\
\hline A1 & 2 & $0.250 \pm 0.002$ & 108 \\
\hline A2 & 4 & $0.261 \pm 0.001$ & 117 \\
\hline A3 & 6 & $0.365 \pm 0.002$ & 204 \\
\hline A4 & 8 & $0.422 \pm 0.002$ & 252 \\
\hline
\end{tabular}

*Readings are average mean of 3 set of flasks

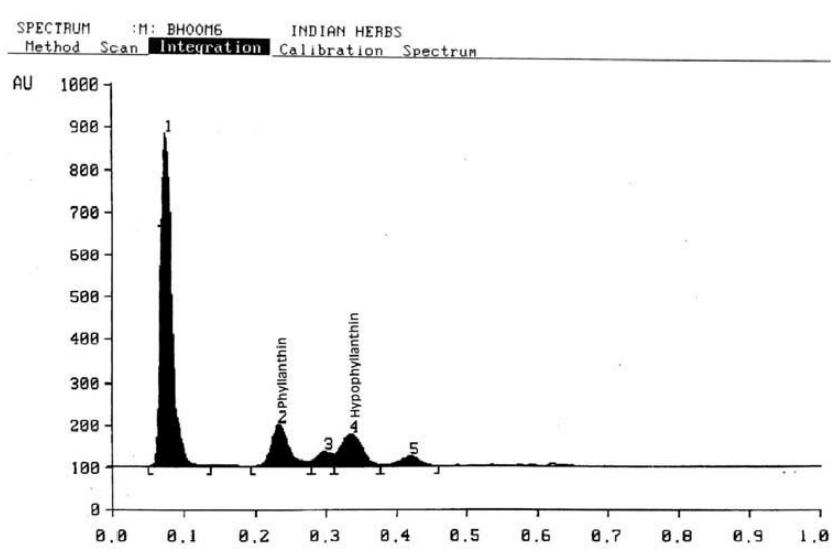

Fig. 5. HPTLC chromatogram showing metabolite production profile of immobilized $P$. amarus cells by medium elicitation with $8 \mathrm{~mL}$ Cinnamic acid.

\section{ESTIMATION OF PHYLLANTHIN AND HYPOPHYLLANTHIN}

For quantification of phyllanthin and hypophyllanthin in $P$. amarus suspension and immobilized cells of 14 day samples from MS medium in incubator cum shaker, stock solutions of phyllanthin and hypophyllanthin were prepared by HPTLC grade methanol, to obtain concentration of $200 \mu \mathrm{g}$ and calibration curves were plotted, using HPTLC-integration by CAMAG TLC evaluation software. HPTLC precoated plates at $60^{\circ} \mathrm{F} 254$ (Merck), automatic sample III (CAMAG) were used and integrated with CATS V4.06, S/N : 0511A011/Sc3 V1.14, S/N: 041123. HPTLC Plates $(20$ x $20 \mathrm{~cm})$ were developed using Hexane: Ethyl acetate solvent system (2:1) (Application mode CAMAG Automatic TLC Sampler III, Development mode CAMAG Twin Trough Chamber).[4] 
Calibration curves were plotted showing peak height and distance travelled by peak after calculating the factor $x$ area divided by amount of sample applied and the percentage (w/w) of phyllanthin and hypophyllanthin was calculated in different treated and control samples as their concentration as reported.[5] In the chromatogram the 1st peak seen was of chlorophyll and 2nd peak of phyllanthin, 4th peak of hypophyllanthin, while the other peaks which are seen are of other unidentified lignans, terpenes etc. present in P. amarus, apart from phyllanthin and hypophyllanthin.

\section{RESULTS AND DISCUSSION}

After immobilization of cell culture of $P$. amarus in calcium alginate beads in MS medium, studies were carried out to find out the impact of supplementation with Chitosan, Kinetin, Naphthalene acetic acid and Cinnamic acid under aseptic conditions after immobilization on the increased accumulation of secondary metabolites to enhance the production of phyllanthin and hypophyllanthin as compared to control.

It is reported that an optimal concentration of suitable sterilizing agent with ideal exposure period depends on the nature of plant for successful surface sterilization of the leaves. The earlier reports suggested that $0.01 \% \mathrm{w} / \mathrm{v}$ mercuric chloride was found suitable for surface sterilization of leaves.

MS medium was modified by adding Chitosan, Kinetin, Naphthalene acetic acid and Cinnamic acid solution, [precursors and phytohormones] for enhancing of P. amarus bioactives in immobilized cells.

Kinetin treatment: Immobilized $P$. amarus cell system in low concentration, solutions of 5, 10 and $20 \mathrm{~mL}$ in $\mathrm{MS}$ medium showed increase in the yield of phyllanthin and hypophyllanthin by $0.122,0.124$ and $0.126 \%$ w/w respectively which was maximum $5 \%$ enhancement with 20 $\mathrm{mL}$ kinetin solution as compared to control (0.120\%) immobilized cell culture. (Table 1) Cytokinetins are reported to increase marginally sennoside content in senna leaves and also enhance the dry weight of shoots. Kinetin stimulated the production of anthocyanins in Halpopappus gracilus cell cultures [5].

Naphthalene acetic acid treatment: Immobilized cell system of P.amarus in M.S. medium with 5,10 and $20 \mathrm{~mL}$ of $1 \%$ solution of Naphthalene acetic acid showed increase in the yield of bioactives by $0.175,0.210$ and $0.225 \%$ respectively. The maximum enhancement of phyllanthin and hypophyllanthin was $88 \%$ with $20 \mathrm{~mL}$ of Naphthalene acetic acid treatment when compared to control immobilized cultures (Table 2). Naphthalene acetic acid has been shown to enhance the production of nicotine in suspension of $N$. tabacum and of Shikonin in suspensions of L. erythrorhizon [6], [7].

Chitosan treatment: Immobilized cell system of P.amarus in MS medium showed maximum enhancement in the yield of phyllanthin and hypophyllanthin with $20 \mathrm{ml}$ of $1 \%$ solution of chitosan. It was $238 \%$ when compared to control immobilized cell cultures after HPTLC analysis (Table III). The entrapment efficiency of chitosan depends on elicitor specificity, cell line of elicitor used, presence of growth regulators, composition of culture medium and the environmental conditions.

Elicitation of immobilized plumbago rosea cells with chitosan proved highly effective by using an extracellular site for the product accumulation where plumbogin production was increased about 21 times by collective use of immobilization, elicitation and two phase culture [8].

TABLE V: COMPARATIVE ENHANCEMENT OF PHyllanthin AND HYPOPHYLLANTHIN IN IMMOBILIZED CELL SYSTEM WITH DIFFERENT TREATMENTS

\begin{tabular}{|l|l|l|l|}
\hline $\begin{array}{c}\text { S. } \\
\text { No. }\end{array}$ & \multicolumn{1}{|c|}{ Treatment } & $\begin{array}{c}\text { Phyllanthin and } \\
\text { Hypophyllanthin (w/w) }\end{array}$ & $\begin{array}{c}\text { Percentage } \\
\text { enhancement }\end{array}$ \\
\hline 1 & Control & 0.120 & 0 \\
\hline 2 & Kinetin & 0.126 & 5 \\
\hline 3 & $\begin{array}{l}\text { Naphthalene } \\
\text { acetic acid }\end{array}$ & 0.225 & 88 \\
\hline 4 & Chitosan & 0.405 & 238 \\
\hline 5 & Cinnamic acid & 0.422 & 252 \\
\hline
\end{tabular}

Cinnamic acid treatment: It was observed that MS medium with immobilized cell system of P.amarus, after addition of $8 \mathrm{~mL} 1 \%$ solution of cinnamic acid showed $252 \%$ maximum enhancement of phyllanthin and hypophyllanthin content when compared to control immobilized cultures (Table IV). It is reported that increased yield of capsaicin and dihydrocapsaicin were obtained when immobilized placental tissue of $C$. frutescens was treated with cinnamic acid, caffeic acid and ferulic acid [9].

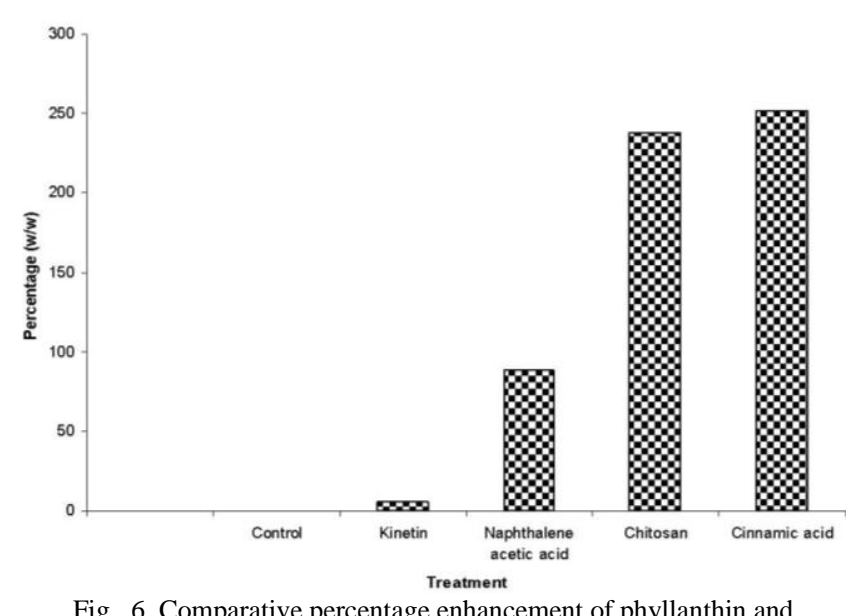

Fig . 6. Comparative percentage enhancement of phyllanthin and hypophyllanthin in immobilized cell system of P.amarus

\section{CONCLUSION}

Immobilized cell cultures of $P$. amarus with different treatments in MS media, the content of phyllanthin and hypophyllanthin enhanced with $1 \%$ solution of kinetin $5 \%$ followed by napthalene acetic acid $88 \%$, chitosan $238 \%$ and maximum with cinnamic acid $252 \%$ when compared to control sample $0.120 \%$ (Table 5, Fig.6). A graph was plotted to show the percentage increase with different treatments in immobilized cell system of $P$. amarus and compared with control in which the percentage enhancement of phyllanthin and hypophyllanthin was reported.

Cell viability studies were also done for P. amarus in MS medium in each supplementation and elicitation, by U.V. florescence microscope and it was found that $66 \%$ cells were living cells in the immobilized cell cultures.

On the basis of HPTLC analysis of control as well as treated samples of $P$. amarus immobilized cell system, it was found that there was maximum increase in phyllanthin and 
hypophyllanthin yield using cinnamic acid followed by chitosan, napthalene acetic acid and kinetin as precursors and phytohormones when compared to control $(0.120 \%)$.

The study revealed that addition of kinetin, napthalene acetic acid, chitosan and cinnamic acid as precursors and phytohormones in the MS medium enhanced maximum production of phyllanthin and hypophyllanthin in immobilized $P$. amarus cells as compared to control sample.

The production of hepatoprotective bioactives, phyllanthin and hypophyllanthin in $P$. amarus enhanced by immobilization cell system in MS medium by supplementing with different precursors and phytohormones reported after HPTLC analysis.

\section{ACKNOWLEDGEMENT}

The author is thankful to Mr. Sudhakar Agarwal, Director, Indian Herbs and Research Supply Co. Saharanpur (U.P.) India, for helping in HPTLC analysis.

\section{REFERENCE}

[1] K. V. Syamasundar and B. Singh, "Antihepatotoxic principles of Phyllanthus niruri herb,” J. Ethnopharmcol., 14: 41-44, 1985.
[2] C. K. Atal and B. M. Kappor, Cultivation and Utilization of Medicinal Plants, C. S. I. R., New Delhi, 282, 1982.

[3] K. R. Aneja, Experiments in Microbiology, Plant Pathology and Biotechnology, New Age International (P) Ltd., New Delhi, 228-230, 2005.

[4] A. Sharma, R. T. Singh, and S. S. Handa, Estimation of phyllanthin and hypophyllanthin by high performance liquid chromatography in Phyllanthus amarus, Phytochem. Anal., 4: 226-229, 1993.

[5] V. Rajpal, Standardization of Botanicals, Testing and Extraction methods of medicinal herbs, Eastern Publishers, New Delhi, I: 184-192, 2002.

[6] H. U. Seitz and W. Hinderer, Anthocyanins in Cell culture and somatic cell genetics of plants, Academic Press, San Diego, 5: 49-76, 1988.

[7] L. Rajendran, G. Suvaoranlatha, G. A. Ravishanker, and C. Venkeatraman, "Elicitation of anthocyanin production," in cell cultures of carrot (Daucus carota) using elicitors and abiotic stress, Biotech. Lett., 16(12): 1275-1280, 1994.

[8] P. Komaraiah, "Enhanced production of plumbagin in immobilized cells of plumbago rosea by elicitation and in situ adsorption", $J$. Biotech., 101: 181-187, 2003.

[9] T. J. Sudhakar and Ravishankar, Precursor biotransformation in immobilized placental tissues of Capsium frutescens mill: II, Influence of feeding intermediates of the capsaicinoid pathway in combination with L-valine on capsaicin and dihydrocapsaicin accumulation, J. Plant Physio, 153: 240-243, 1998. 